\title{
The Nutritional Regulation of Circulating Placental Lactogen in Fetal Sheep
}

\author{
M. H. OLIVER, J. E. HARDING, B. H. BREIER, P. C. EVANS, AND P. D. GLUCKMAN
}

Department of Paediatrics, University of Auckland, Auckland, New Zealand

\begin{abstract}
Maternal and fetal plasma ovine placental lactogen (oPL), insulin, and IGF-I levels were measured in response to the starvation and refeeding of pregnant sheep on two defined planes of nutrition. Chronically catheterized pregnant ewes were placed on either a high plane $(n=5)$ or low plane $(n=5)$ of nutrition at least 1 wk before the experiment. At 125 to 135 d gestation, the ewes were starved for $72 \mathrm{~h}$ and then an i.v. infusion of $10 \%$ glucose was administered over $4 \mathrm{~h}$, followed by refeeding at the designated nutritional plane. Plasma oPL levels of fetuses whose mothers had been on a high plane of nutrition were significantly higher during starvation $(p<0.05)$ than those of fetuses whose mothers had been on a low plane (high + $0.54 \pm 0.17$ and low $-0.02 \pm 0.17 \mathrm{nmol} / \mathrm{L}$ from mean control levels). Intravenous glucose infusion to the ewes at the end of starvation caused a marked rise in fetal plasma oPL levels in both groups (increments of $2.61 \pm 1.4 \mathrm{nmol} /$ $L$ in the high group and $2.81 \pm 1.16 \mathrm{nmol} / \mathrm{L}$ in the low group). Maternal oPL levels did not differ significantly between the two nutritional groups during starvation and did not change during glucose infusion. Fetal and maternal plasma IGF-I levels both fell during starvation. Maternal IGF-I levels fell faster in the high group $(-17.9 \pm 4.5$ at $24 \mathrm{~h}$ versus $-4.7 \pm 7.2 \mathrm{nmol} / \mathrm{L}$ in the low group), but the groups were not different at the end of starvation. There were significant differences $(p<0.05)$ in maternal and fetal plasma insulin levels between the two groups during starvation. The fall in maternal and fetal plasma insulin was greater in the high group (fetal $-0.13 \pm 0.06$ and maternal $-0.25 \pm 0.13 \mathrm{nmol} / \mathrm{L}$ ) versus the low group (fetal $-0.01 \pm 0.01$ and maternal $-0.02 \pm 0.08 \mathrm{nmol} / \mathrm{L}$ ). These observations demonstrate that preexisting maternal nutritional status affects oPL responses to acute starvation and that oPL may have a role in metabolite partitioning between mother and fetus. (Pediatr Res (31: 520-523, 1992)
\end{abstract}

\section{Abbreviations}

PL, placental lactogen

$\mathrm{oPL}$, ovine placental lactogen

PL is found in both the maternal and fetal circulations (1). PL may have a role in the supply of carbohydrates to the fetus through its lipolytic actions $(2,3)$ and the induction of insulin resistance in the mother (4). However, an antibody neutralization study by Waters et al. (5) questions any role PL may have in

Received June 20,1991; accepted January 22,1992.

Correspondence: P. D. Gluckman, Developmental Physiology Laboratory, Department of Paediatrics, University of Auckland, Private Bag, Auckland, New Zealand.

Supported by grants from the Medical Research Council (NZ), the National Child Health Research Foundation (NZ), and the Foundation for the Newborn (NZ). carbohydrate metabolism. In the fetus, PL has been suggested to have a role in the regulation of fetal growth; however, there is no direct supporting evidence. Any effect on fetal growth may be indirect through alterations in the maternal metabolic environment or may be mediated through stimulation of IGF release (6). The actual role of PL in both compartments remains obscure. Insulin and IGF have long been considered to have either permissive or regulatory roles in promoting fetal growth (7). Placental lactogen, IGF, and insulin are likely to interact in the regulation of fetal growth. For example, an in vitro study (8) has demonstrated a releasing action of both IGF-I and insulin on PL in human term placental explants. Insulin and PL also act in a synergistic fashion to promote glycogen synthesis (9) and inhibit glycogenolysis in fetal rat hepatocytes (10). Similar specific actions of oPL on glycogen synthesis in the fetal ovine liver have been reported, and the possibility of specific oPL receptors has been suggested (11).

Most investigations into the role of PL in pregnancy have concentrated on actions in the maternal compartment. Conflicting data are reported on the effects of nutrition on maternal oPL secretion. For example, in one study, starvation for $72 \mathrm{~h}$ was reported to have little influence on maternal PL levels (12). However, in other sheep studies using a similar period of starvation or longer term nutritional restriction caused an elevation in both maternal and fetal PL levels by 40 to $50 \%$ (13). Two early studies in humans $(14,15)$ and a later study in rats (16) report significant increases in maternal oPL levels after $72 \mathrm{~h}$ of starvation. Freemark et al. (17) demonstrated that fetal oPL increased significantly after a 3-d period of maternal starvation. However, such studies have generally ignored the potential confounding influence of the long-term nutritional status of the mother in determining the response to nutritional deprivation.

Because the existing nutritional status of a mother may affect both fetal and maternal PL levels, and in view of the potential role of PL in the regulation of fetal growth, we investigated the influence of the prior nutritional status of the mother on fetal PL responses to acute changes in maternal nutrition.

\section{MATERIALS AND METHODS}

Ten Coopworth/Border cross-bred ewes were acclimatized to feeding regimens and laboratory conditions at least 1 wk before surgery. Five ewes were placed on a high plane of nutrition, i.e. over $1600 \mathrm{~g}$ of feed concentrates per day (NRM Multi-Feed Sheep Nuts, Auckland, New Zealand) and five ewes were placed on a low plane of nutrition, less than $500 \mathrm{~g}$ of concentrates per day. Ad libitum feeding with barley straw of very low nutrient value was provided for bulk. At 118 to $123 \mathrm{~d}$ gestation, polyvinyl catheters were surgically inserted with the ewes under halothane anesthetic, into the tarsal veins and arteries of both fetal hind legs and the carotid artery and jugular vein of the mother. After surgery, the ewes were allowed at least $5 \mathrm{~d}$ to recover during which time they continued their specific feeding regimens.

The experimental protocol consisted of a 2-d control period followed by $3 \mathrm{~d}$ of maternal starvation. The starvation was 
terminated on the 3 rd d by an i.v. $500-\mathrm{mL}$, 4-h infusion of $10 \%$ dextrose to the mother (18), followed by a $2-\mathrm{d}$ period of refeeding on the previous nutritional plane. Blood sampling was performed daily in the morning before normal feeding time and in the afternoon $8 \mathrm{~h}$ later. On the 3rd d of starvation, an additional sample was taken after the completion of the dextrose infusion. Previous studies in our laboratory have shown little diurnal variation in fetal oPL concentrations. Blood samples were collected in sterile heparinized syringes and centrifuged at $4^{\circ} \mathrm{C}$, and the plasma was stored at $-20^{\circ} \mathrm{C}$ until RIA for oPL, IGF-I, and insulin. Experimental protocols were approved by the institutional animal ethics committee.

For the oPL RIA, recombinant oPL (a gift of Dr. R. Vandlen, Genentech, South San Francisco, CA) was iodinated by a modification of the lactoperoxidase method (1) and the ${ }^{125}$ I-oPL was then purified by exclusion gel chromatography on a Sephadex G-100 column $(90 \times 1.1 \mathrm{~cm}$; Pharmacia, Uppsala, Sweden $)$ using $0.05 \mathrm{M}$ barbitone, $\mathrm{pH} 8.6$, as the eluting buffer. The incubation volume was $500 \mu \mathrm{L}$, and a rabbit anti-oPL antiserum (RASPL\#1) was used at a final concentration of $1: 150000$. This antiserum had been raised to a purified preparation of oPL (19). The assay consisted of a $48 \mathrm{~h}$ preincubation period at $4^{\circ} \mathrm{C}$ in which $300 \mu \mathrm{L}$ of the antibody mixture was added to tubes containing $100 \mu \mathrm{L}$ of standard or sample diluted in assay buffer. The tracer, diluted to $100 \mu \mathrm{L} /$ tube $(25000 \mathrm{cpm})$, was then added, and the incubation continued for another $24 \mathrm{~h}$ at room temperature. Free and bound tracer were separated by the addition of sheep anti-rabbit gamma globulin, normal rabbit serum, and polyethylene glycol 6000 . The minimal detectable dose was $0.05 \mathrm{ng} /$ tube, half displacement was achieved at $0.6 \mathrm{ng} /$ tube, the intraassay coefficient of variation was $5.1 \%$, and the interassay coefficient of variation was 9.7\%. Values are expressed in terms of recombinant oPL (batch no. 11380/77, Genentech).

Plasma IGF-I was measured by RIA (20) using rabbit antiserum to recombinant human metIGF-I $(878 / 4)$ at a final titer of 1:150 000 . The antiserum has a cross-reaction with IGF-II of $<0.1 \%$, a minimal detectable dose of $0.06 \mathrm{ng} /$ tube, and a half displacement dose of $0.40 \mathrm{ng} /$ tube. Before immunoassay, plasma samples were subjected to acid-ethanol cryoprecipitation extraction. Using this system, the intraassay coefficient of variation was $5.0 \%$ and the interassay coefficient of variation was $9.8 \%$. Plasma IGF-I concentrations are expressed in terms of World Health Organization reference standard IRRIGF-I batch $87 / 518$ (National Institute for Biological Standards and Control, Potters Bar, Hertz, UK). The full validation of this assay system for fetal and adult sheep plasma has been reported (20).

Plasma insulin was assayed as described previously (21) using guinea pig anti-ovine insulin antiserum (GC4) at a titer of 1:200 000. The cross-reactivity with IGF-I and IGF-II was less than $0.01 \%$. The intraassay coefficient of variation was $6.7 \%$, and the interassay coefficient of variation was $11.5 \%$.

Hormone values are expressed as means $\pm \mathrm{SD}$. The interanimal variation of PL levels in this study, and as reported in other studies $(13,22)$, was high, so the data from the nutritional manipulations was normalized relative to the control values (four samples taken over $2 \mathrm{~d}$ ) of each animal before comparisons were made between groups. Hormone concentrations were compared between the two nutritional groups using two-way analysis of variance with repeated measures, and differences at each point during starvation were compared using factorial analysis of variance with Sheffe's correction for multiple comparisons. Hormone concentrations during starvation and refeeding were evaluated using absolute data and analysis of variance with Sheffe's correction. Significant differences were accepted at the $5 \%$ level.

\section{RESULTS}

During the control period, fetal oPL levels in the high nutrition group tended to be lower than those from the low nutrition group (Table 1) but the difference did not reach significance. During the maternal fast, fetuses whose mothers had been on a high plane of nutrition had plasma oPL levels significantly higher $(p$ $<0.05$ ) than those whose mothers had been on a low plane of nutrition (Fig. 1). Maternal i.v. dextrose infusion caused a rapid increase in fetal plasma oPL levels in both groups, although only the increase in the low nutrition group reached statistical significance $(p<0.05)$. Fetal oPL levels remained high during the following $40 \mathrm{~h}$ of maternal ad libitum refeeding in both groups.

Maternal oPL levels during the control period were not significantly different between the two nutritional groups. During starvation, maternal plasma oPL tended to be higher in the low nutrition group (Fig. 1) but the difference did not reach statistical significance. There was no change in maternal plasma oPL after maternal glucose infusion, but after ad libitum refeeding the difference between the groups decreased.

Placental weight was not strongly correlated $\left(r^{2}=0.24, p<\right.$ 0.05 ) with maternal plasma oPL levels, but placental weight was close to significant difference $(p<0.06)$ between the two groups. Fetal weight was not significantly different between groups.

Fetal plasma IGF-I concentrations were not significantly different between the two nutritional groups during the control period. During maternal starvation, fetal IGF-I levels fell in both groups, although the change reached statistical significance only in the low nutrition group (Fig. 2, Table 1).

Maternal plasma IGF-I during the control period (Table 1) was lower in the low nutrition group $(p<0.05)$. During starvation, maternal IGF-I levels fell in both groups, but the fall was more rapid in the high nutrition group (Fig. 2, Table 1). During the refeeding phase, there was a gradual increase toward control IGF-I levels in both groups (Fig. 2, Table 1).

Fetal and maternal plasma insulin levels were not different between the two groups during the control period and fell gradually during starvation. This fall was more rapid in the high nutrition group, so that both fetal and maternal insulin levels were significantly lower $(p<0.05)$ in the high nutrition group than in the low nutrition group during the early phase of maternal starvation (Fig. 3). Maternal infusion of dextrose caused a marked increase in plasma insulin levels in both fetus and mother, which was followed by a return to control values during refeeding (Fig. 3, Table 1 ).

\section{DISCUSSION}

This study demonstrated that prior maternal nutritional status influenced the fetal plasma oPL response to maternal starvation. The reason for the difference between the nutritional groups is unclear.

In the mother, oPL is postulated to protect fetal substrates through preferential induction of lipolysis (2). The relatively high oPL levels seen in fetuses from well-nourished mothers during starvation could suggest that the hormone is functioning in a similar fashion in the fetus. In the fetuses from poorly nourished ewes, it is possible that a similar response did not occur or was delayed. Alternatively, the number of fetal oPL receptors may differ in the two nutritional groups. It has been reported that fetal oPL receptors are reduced in number after $72 \mathrm{~h}$ of maternal fasting in sheep (17). In the current study, after a similar period of starvation, a reduction in the number of fetal oPL receptors could be associated with an increase in fetal plasma oPL levels in fetuses from well-nourished mothers. If in fetuses from undernourished mothers the oPL receptors had been down-regulated before the period of starvation, compensatory increases in fetal plasma oPL would be unlikely.

The acute rise in fetal plasma oPL seen during maternal infusion of dextrose was not expected. Indeed, the opposite effect might have been expected, given that PL may have a substratereleasing action postnatally (2). However, in human term placental explants, physiologic concentrations of glucose had a releasing action on PL secretion (23). Recent in vitro studies also demonstrated that PL acts in synergy with insulin to promote glycogen 
Table 1. Maternal and fetal plasma hormone concentrations*

\begin{tabular}{|c|c|c|c|c|}
\hline & \multicolumn{2}{|c|}{ Maternal } & \multicolumn{2}{|c|}{ Fetal } \\
\hline & Low nutrition & High nutrition & Low nutrition & High nutrition \\
\hline \multicolumn{5}{|l|}{ oPL } \\
\hline $72 \mathrm{~h}$ & $18.56 \pm 7.46$ & $19.11 \pm 7.97$ & $1.20 \pm 0.26$ & $1.84 \pm 0.66$ \\
\hline Post inf & $15.96 \pm 6.94$ & $21.66 \pm 5.88$ & $4.01 \pm 1.41 \dagger$ & $3.75 \pm 1.78$ \\
\hline End & $20.47 \pm 9.61$ & $15.51 \pm 4.56$ & $1.16 \pm 0.46 \dagger$ & $1.37 \pm 0.16 \dagger$ \\
\hline $72 \mathrm{~h}$ & $11.56 \pm 5.62$ & $15.61 \pm 5.86 \dagger$ & $7.83 \pm 1.54 \dagger$ & $7.57 \pm 2.18$ \\
\hline Post inf & $9.74 \pm 5.33$ & $13.56 \pm 3.33$ & $8.43 \pm 2.13$ & $8.92 \pm 2.76$ \\
\hline End & $20.19 \pm 11.81$ & $20.89 \pm 3.54$ & $9.98 \pm 1.62$ & $9.81 \pm 3.31$ \\
\hline \multicolumn{5}{|l|}{ Insulin } \\
\hline Control & $0.29 \pm 0.17$ & $0.38 \pm 0.1$ & $0.23 \pm 0.15$ & $0.31 \pm 0.13$ \\
\hline $72 \mathrm{~h}$ & $0.18 \pm 0.07$ & $0.12 \pm 0.06$ & $0.25 \pm 0.15$ & $0.18 \pm 0.09$ \\
\hline
\end{tabular}

* Values, expressed as nmol/L, are means \pm SD for five animals in each group. Control, last measurement before starvation; $72 \mathrm{~h}$, value after 72 $\mathrm{h}$ of starvation; post inf, value after $4 \mathrm{~h}$ of maternal dextrose infusion; End, value after $40 \mathrm{~h}$ of ad libitum refeeding.

$\dagger$ Significantly different than earlier value in same group $(p<0.05)$.
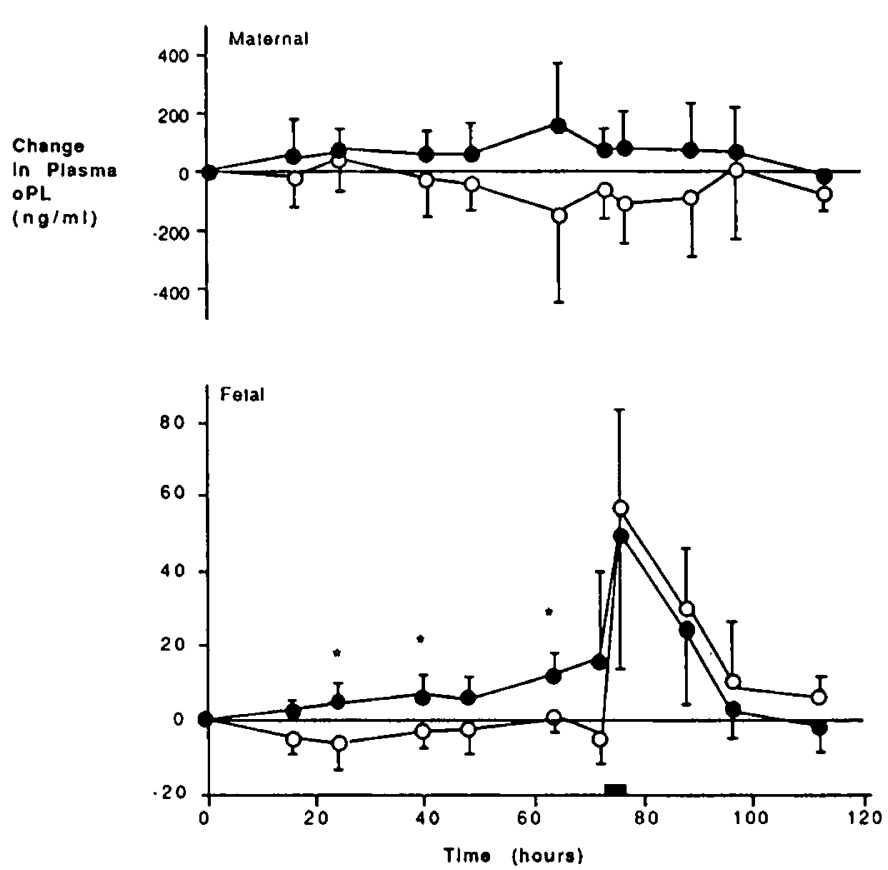

Fig. 1. Maternal and fetal plasma oPL responses to maternal starvation and refeeding. Values are mean $\pm \mathrm{SD}$, calculated for the change from mean baseline oPL level for each animal $(10 \mathrm{ng} / \mathrm{mL}=0.46 \mathrm{nmol} /$ L). Starvation began at $0 \mathrm{~h}$. The solid bar indicates i.v. dextrose infusion to the mother. Filled circles, high nutritional plane $(n=5)$. Open circles, low nutritional plane $(n=5)$. ${ }^{*}$, Significant differences between the nutritional groups $(p<0.05)$.

synthesis (9) and inhibit glycogenolysis (10) in fetal rat hepatocytes. Similarly, in human term placental explants in vitro, IGFI and insulin induce an increase in PL content in culture medium (8). The large increases in fetal oPL and insulin seen in the current study after the dextrose infusion may reflect these actions in vivo.

The large variation in the maternal levels of oPL between animals has been reported previously $(12,13)$, and it is likely to be representative of varying placental size and, therefore, nutritional status at the time of placental implantation and growth. However, in this study there was little correlation between maternal oPL and placental weight, even though placental weight was close to being significantly different between the two groups.
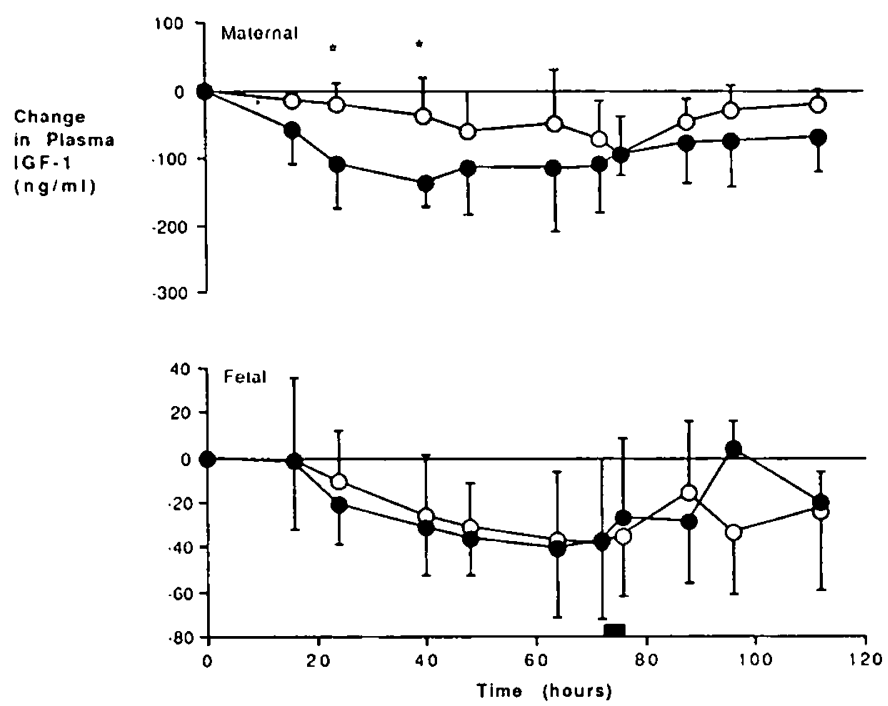

Fig. 2. Maternal and fetal plasma IGF-I responses to maternal starvation and refeeding. Values are mean $\pm \mathrm{SD}$, calculated for the change from mean baseline IGF-I level for each animal ( $1 \mathrm{ng} / \mathrm{mL}=0.13 \mathrm{nmol} /$ L). Starvation began at $0 \mathrm{~h}$. The solid bar indicates i.v. dextrose infusion to the mother. Filled circles, high nutritional plane $(n=5)$. Open circles, low nutritional plane $(n=5)$. ${ }^{*}$, Significant differences between the nutritional groups $(p<0.05)$.

In the mother, it has often been reported $(12,22)$ that plasma oPL varies considerably in the individual animal over time, apparently showing no clear rhythm, so this has the effect of masking any changes in hormone levels in response to various experimental manipulations. From our experience, this is not so in the fetus. However, during starvation the trend toward different maternal plasma oPL responses between the two groups was consistent with that seen in the fetus.

There was no maternal plasma oPL response after dextrose infusion, even though maternal plasma insulin showed a significant increase, suggesting that the functional relationship between glucose, insulin, and PL differs in the adult and the fetus. Other studies in the pregnant ewe, however, demonstrated that maternal oPL secretion increases after the infusion of other metabolic substrates such as some amino acids $(24,25)$ and HDL (26).

The relationship between maternal nutritional status and levels of circulating IGF-I has been reported previously in sheep (19), and the maternal IGF-I results presented here are consistent with 

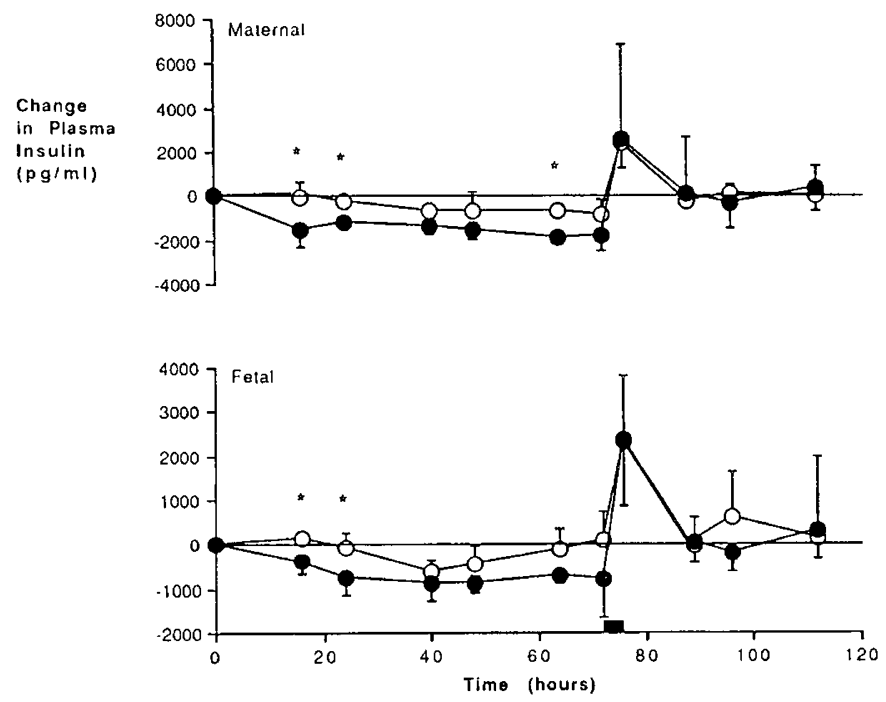

Fig. 3. Maternal and fetal plasma insulin responses to maternal starvation and refeeding. Values are mean $\pm \mathrm{SD}$, calculated for the change from mean baseline insulin level for each animal $(1000 \mathrm{pg} / \mathrm{mL}=0.17$ $\mathrm{nmol} / \mathrm{L})$. Starvation began at $0 \mathrm{~h}$. The solid bar indicates i.v. dextrose infusion to the mother. Filled circles, high nutritional plane $(n=5)$. Open circles, low nutritional plane $(n=5) .{ }^{*}$, Significant differences between the nutritional groups $(p<0.05)$.

earlier observations. Maternal plasma IGF-I levels were higher in the high nutrition group during the control period and fell more dramatically than in the low nutrition group during starvation. Fetal IGF-I responses to starvation and refeeding in this study were similar to those in an earlier study by our group (18).

In summary, this study demonstrates that long-term maternal nutritional status influences fetal oPL responses to maternal starvation. The results highlight the critical importance of defining preexisting maternal nutritional status in any study of fetal oPL, IGF-I, or insulin and their relationship to substrate levels and placental function. The increase in fetal plasma oPL after maternal i.v. dextrose infusion suggests a synergistic anabolic action with insulin in the fetus. The maternal data obtained after the dextrose infusion suggests that glucose has a different functional role in the regulation of oPL in the fetus and mother. The direct effects of oPL on maternal and fetal carbohydrate metabolism and endocrine function require further investigation to gain a better understanding of the role of PL in fetal growth.

Acknowledgments. The authors thank Christine Gibson, Brian Gallaher, Fiona Ffolliott-Powell, David Blowers, and Li Liu for their technical assistance.

\section{REFERENCES}

1. Gluckman PD, Kaplan SL, Rudolph AM, Grumbach MM 1979 Hormone ontogeny in the ovine fetus. II. Ovine chorionic somatomammotropin in mid-and late-gestation in the fetal and maternal circulations. Endocrinology 104:1828-1833

2. Thordarson G, McDowell GH, Smith SV, Iley S, Forsyth IA 1987 Effects of continuous intravenous infusion of an ovine placental extract enriched in placental lactogen on plasma hormones, metabolites and metabolite biokinetics in non-pregnant sheep. J Endocrinol 113:277-283

3. Handwerger S, Fellows RE, Crenshaw MC, Hurley T, Barrett J, Maurer WF 1976 Ovine placental lactogen: acute effects on intermediary metabolism in pregnant and non-pregnant sheep. J Endocrinol 69:133-137

4. Ryan EA, Enns L 1988 Role of gestational hormones in the induction of insulin resistance. J Clin Endocrinol Metab 67:341-347

5. Waters MJ, Oddy VH, McCloghry CE, Gluckman PD, Duplock R, Owens PC, Brinsmead MW 1985 An examination of the proposed roles of placental lactogen in the ewe by means of antibody neutralisation. J Endocrinol 106:377-386

6. Swenne I, Hill DJ, Strain AJ, Milner RDG 1987 Effects of human placental lactogen and growth hormone on the production of insulin and somatomedin C/insulin-like growth factor I by human fetal pancreas in tissue culture. J Endocrinol 113:297-303

7. Gluckman PD, Breier BH, Oliver MH, Harding J, Bassett N 1990 Fetal growth in late gestation: a constrained pattern of growth. Acta Paediatr Scand [Suppl] 367:105-110

8. Bhaumick B, Dawson EP, Bala RM 1987 The effects of insulin-like growth factor-I and insulin on placental lactogen production by human term explants. Biochem Biophys Res Commun 144:674-682

9. Freemark M, Handwerger S 1984 Synergistic effects of ovine placental lactogen and insulin on glycogen metabolism in fetal rat hepatocytes. Am J Physiol 247:E714-718

10. Freemark M, Handwerger S 1985 Ovine placental lactogen inhibits glucagoninduced glycogenolysis in fetal rat hepatocytes. Endocrinology 116:12751280

11. Freemark M, Handwerger S 1986 The glycogenic effects of placental lactogen and growth hormone in ovine fetal liver are mediated through binding to specific fetal ovine placental lactogen receptors. Endocrinology 118:613-618

12. Butler WR, Huyler SE, Giradis AS, Handwerger S 1987 Failure of fasting and changes in plasma metabolites to affect spontaneous fluctuations in plasma concentrations of ovine placental lactogen. J Endocrinol 114:391-397

13. Brinsmead MW. Bancroft BJ, Thorburn GD, Waters MJ 1981 Fetal and maternal ovine placental lactogen during hypoglycaemia and fasting. $\mathrm{J}$ Endocrinol 90:337-343

14. Tyson JE, Austin KL, Farinholt JW 1971 Prolonged nutritional deprivation in pregnancy: changes in human chorionic somatomammotropin and growth hormone secretion. Am J Obstet Gynecol 108:1080-1082

15. Kim YT, Felig P 1971 Plasma chorionic somatomammotropin levels during starvation in mid pregnancy. J Clin Endocrinol Metab 32:864-867

16. Fielder PJ, Ogren L, Edwards D, Talamantes F 1987 Effects of fasting on serum lactogenic hormone concentrations during mid- and late pregnancy in mice. Am J Physiol 253:E40-E44

17. Freemark M, Comer M, Mularoni T, D'Ercole AG, Kodack L 1989 Nutritional regulation of the placental lactogen receptor in fetal liver: implications for fetal metabolism and growth. Endocrinology 125:1504-1512

18. Bassett NS, Oliver MH, Breier BH, Gluckman PD 1990 The effect of starvation on fetal IGF-I. Pediatr Res 27:401-404

19. Gluckman PD, Barry TN 1988 Relationships between plasma concentrations of placental lactogen, insulin-like growth factors, metabolites and lamb size in late gestation ewes subject to nutritional supplementation and in their lambs at birth. Domest Anim Endocrinol 5:209-217

20. Breier BH, Gallaher BW, Gluckman PD 1991 Radioimmunoassay for insulinlike growth factor-1: solutions to some potential problems and pitfalls. J Endocrinol 128:347-357

21. Breier BH, Gluckman PD, Bass JJ 1988 Plasma concentrations of insulin-like growth factor-I and insulin in the infant calf: ontogeny and influence of altered nutrition. J Endocrinol 119:43-50

22. Taylor MJ, Jenkin G, Robinson GD, Thorburn HF, Chan JSD 1980 Concentrations of placental lactogen in chronically catheterised ewes and fetuses in late pregnancy. J Endocrinol 85:27-34

23. Belleville F, Lasbennes A, Nabet $P$, Paysant $P 1979$ HCS regulation in cultured placenta: action of glucose. Acta Endocrinol (Copenh) 92:336-346

24. Handwerger S, Grandis A, Barry S, Crenshaw MC 1981 Stimulation by ornithine of ovine placental lactogen secretion. J Endocrinol 88:283-288

25. Handwerger S, Crenshaw MC, Lansing A, Golander A, Hurley TW, Fellows RE 1978 Stimulation of ovine placental lactogen secretion by arginine infusion. Endocrinology 103:1752-1758

26. Grandis A, Jorgensen V, Kodack L, Quarfordt S, Handwerger S 1989 High density lipoproteins (HDL) stimulate placental lactogen secretion in pregnant ewes: further evidence for a role of HDL in placental lactogen secretion during pregnancy. J Endocrinol 120:423-427 